Smits, M., Wagner, C., Spreeuwenberg, P., Timmermans, D.R.M., Wal, G. van der, Groenewege, P.P. The role of patient safety culture in the causation of unintended events in hospital. Journal of Clinical Nursing: 2012, 21(23-24), 3392-3401

\begin{tabular}{|l|l|}
\hline $\begin{array}{l}\text { Postprint } \\
\text { Version }\end{array}$ & 1.0 \\
\hline Journal website & http://onlinelibrary.wiley.com/doi/10.1111/.1365-2702.2012.04261.x/abstract \\
\hline Pubmed link & $\underline{\text { http://www.ncbi.nlm.nih.gov/pubmed/23145512 }}$ \\
\hline DOI & 10.1111/j.1365-2702.2012.04261.x \\
\hline
\end{tabular}

This is a NIVEL certified Post Print, more info at http://www.nivel.eu

\title{
The role of patient safety culture in the causation of unintended events in hospitals
}

\author{
MarleEn SMits, Cordula Wagner, Peter SPREeUWENBerg, Danielle RM \\ TimMERMANS, GERRIT VAN DER WAL, PETER P GROENEWEGEN
}

Marleen Smits, PhD, Postdoctoral Researcher, NIVEL, Netherlands Institute for Health Services Research, Utrecht; Cordula Wagner, PhD, Professor, NIVEL, Netherlands Institute for Health Services Research, Utrecht and Department of Public and Occupational Health, EMGO Institute for Health and Care Research, VU University Medical Center, Amsterdam; Peter Spreeuwenberg, MSc, Statistician, NIVEL, Netherlands Institute for Health Services Research, Utrecht; Danielle RM Timmermans, PhD, Professor, Department of Public and Occupational Health, EMGO Institute for Health and Care Research, VU University Medical Center, Amsterdam; Gerrit van der Wal, PhD, MD, Professor, Department of Public and Occupational Health, EMGO Institute for Health and Care Research, VU University Medical Center, Amsterdam; Peter P Groenewegen, PhD, Director and Professor, NIVEL, Netherlands Institute for Health Services Research, Utrecht and Department of Sociology and Department of Human Geography, Utrecht University, Utrecht, The Netherlands

\begin{abstract}
Aims and objectives. To examine whether the relationship between specialty and patient safety is mediated by safety culture.

Background. Research has shown that patient safety in hospitals varies by specialty. The safety culture among healthcare professionals in hospital units is believed to influence safety performance. If there is a mediation effect of safety culture in the relationship between specialty and safety, then safety culture could explain why units vary in performance.

Design. Cross-sectional observational study in 28 units of 20 hospitals in the Netherlands. Units were of three specialties: emergency medicine, surgery and internal medicine.

Methods. Safety culture was measured with the Dutch version of the Hospital Survey on Patient Safety Culture with 11 culture dimensions ( $n=542$; response $56 \%)$. Safety outcomes were types of unintended events (six types). Unintended events were collected through staff reporting ( $\mathrm{n}=1885$ events). Data were examined using multilevel regression analysis.

Results. The overall safety culture in the units did not mediate the relationship between specialty and the safety outcomes (event types), but three of the 11 dimensions showed significant mediation on one or more event types: non-
\end{abstract}


Smits, M., Wagner, C., Spreeuwenberg, P., Timmermans, D.R.M., Wal, G. van der, Groenewegep, P.P. The role of patient safety culture in the causation of unintended events in hospital. Journal of Clinical Nursing: 2012, 21(23-24), 3392-3401

punitive response to error, hospital management support and willingness to report.

Conclusions. Only a few safety culture dimensions mediated the relationship between specialty and some of the outcomes, with 'willingness to report' as the most important mediating factor. Our study did not give strong evidence that specialties differ in performance because of their safety cultures. More research into the causes of variation in patient safety between hospital units is needed. Relevance to clinical practice. Our study could not give support for the claim that safety culture is a key factor affecting patient safety.

\section{INTRODUCTION}

It is increasingly believed that to secure gains in healthcare performance, structural changes such as clinical training, guidelines and information technology will not suffice. Over the past decade, policies have begun to emphasise the importance of developing cultural changes alongside structural reform (Scott et al. 2003a). The culture of an organisation consists of the shared norms, values, behaviour patterns, rituals and traditions of its employees (Schein 1985). Safety culture is a part of organisational culture. It is commonly defined as 'the product of individual and group values, attitudes, perceptions, competencies and patterns of behaviour that determine the commitment to, and the style and proficiency of, an organisation's health and safety management' (Health and Safety Commission 1993, Nieva \& Sorra 2003).

Many countries have studied the safety of patients in their hospitals. A systematic review reported that in $9.2 \%$ of all hospital admissions, one or more adverse events occurred, nearly half (43.5\%) of these were preventable, and $7 \cdot 4 \%$ contributed to death (de Vries et al. 2008). The frequencies with which these events occur vary for different specialties. It is known that surgical hospital units (e.g. general surgery, emergency medicine) have higher rates of adverse events than non-surgical units (e.g. internal medicine, laboratory) (Vincent et al. 2001, Davis et al. 2003, Baker et al. 2004, Zegers et al. 2009). This variation could in part be explained by the kind of work processes that are performed in these different work areas. Healthcare processes differ in complexity and degree of standardisation and, partly because of this, in the extent that they are error-prone. Another possible explanation is the safety culture among healthcare staff. Studies have shown that safety culture varies between units of different specialities within one hospital (Zohar et al. 2007, Hartmann et al. 2008, Singer et al. 2009, Smits et al. 2009). Personnel in non-clinical areas perceive a more positive safety culture than workers in high-hazard units, such as the emergency department, intensive care and operating room (Hartmann et al. 2008, Singer et al. 2009).

Insight into the exact nature of the relationship between safety culture and unintended events is lacking (Davies et al. 2000, Scott et al. 2003a). The 2008 publication of the World Health Organization that outlines the future direction of patient safety research across the world stated that rigorous studies are required to gain information on the relationship between culture and patient safety outcomes (Kitch 2008).

The objective of our study was to gain insight into the role of patient safety culture in the relationship between specialty and safety outcomes. If we find a mediation effect 
Smits, M., Wagner, C., Spreeuwenberg, P., Timmermans, D.R.M., Wal, G. van der, Groenewege, P.P. The role of patient safety culture in the causation of unintended events in hospital. Journal of Clinical Nursing: 2012, 21(23-24), 3392-3401

of safety culture in the relationship between specialty and outcomes, then safety culture could explain why units vary in performance. We examined the following research question: Does patient safety culture mediate the relationship between specialty and the occurrence of different types of unintended events? We examined the mediation effect that is displayed in Box 1.

\section{[BOX 1]}

\section{METHODS}

\section{Study design and instruments}

From October 2006 to February 2008, a cross-sectional observational study was performed to examine unintended events at 28 hospital units of 20 hospitals in the Netherlands: two university hospitals, seven tertiary teaching hospitals and 11 general hospitals. The units were of three different types, representing the core of hospital care: emergency medicine (9 units), surgery (10 units) and internal medicine (7 units). The study period varied from five to 14 weeks per unit, depending on the time it took to collect at least 50 reports. The study protocol was granted ethical approval by the VU University Medical Center review board in Amsterdam.

\section{Hospital Survey on Patient Safety Culture (HSOPS)}

In the first week of each study period, at the start of the collection of event reports, the Dutch version of the Hospital Survey on Patient Safety Culture (HSOPS) (Sorra \& Nieva 2004, Smits et al. 2008) was distributed to measure the safety culture among healthcare professionals in the unit. The HSOPS is a widely used questionnaire that distinguishes multiple dimensions of patient safety culture, such as teamwork, communication openness and non-punitive response to error. The Dutch translation - named COMPaZ - only slightly differs from the original HSOPS, having 11 dimensions instead of 12 and having two items less (Smits et al. 2008). Each dimension consists of two to six items, to be answered on a five-point scale of agreement (strongly disagree, disagree, neutral, agree and strongly agree) or frequency (never, rarely, sometimes, most of the time and always). Examples of items are the following: 'when one area in this unit gets really busy, others help out' and 'staff will freely speak up if they see something that may negatively affect patient care'. Previous research has shown that the psychometric properties are good for the original HSOPS (Sorra \& Nieva 2004, Colla et al. 2005, Sorra et al. 2011) and for COMPaZ (Smits et al. 2008). The internal consistency of the dimensions of COMPaZ was acceptable for ten dimensions $(0.64<\alpha<0.79)$, but for 'adequate staffing,' it was doubtful $(\alpha=0 \cdot 58)$. The construct validity of COMPaZ was good: all dimensions correlated moderately with each other, indicating that there were no two factors measuring the same construct. And, as expected, all dimensions correlated with the outcome variable 'patient safety grade' (Smits et al. 2008). In addition, a previous study has shown significant clustering of answers within units on all safety culture dimensions, meaning that the questionnaire really measures unit culture and not just individual attitudes (Smits et al. 2009). 
Smits, M., Wagner, C., Spreeuwenberg, P., Timmermans, D.R.M., Wal, G. van der, Groenewegeph P.P. The role of patient safety culture in the causation of unintended events in hospital. Journal of Clinical Nursing: 2012, 21(23-24), 3392-3401

\section{Unintended event reporting}

Unintended events were defined as events, no matter how seemingly trivial or commonplace, that were unintentional and could have harmed or did harm a patient (Bhasale et al. 1998). These included not only adverse events - resulting in patient harm - but also near-misses (van der Schaaf 1992, Battles \& Lilford 2003, Kaplan \& Rabin Fastman 2003) and no-harm events (Battles \& Lilford 2003, Kaplan \& Rabin Fastman 2003). Healthcare professionals were asked to make written reports of all unintended events that occurred in their units during the study period. We collected at least 50 reports per unit to gain reliable insight into the various types of unintended events that occurred.

All unintended events were classified by the researcher into one of eight event types: materials and equipment, diagnosis and treatment, medication, protocols and regulations, incorrect data and substitutions, collaboration with resident physicians and consultants, collaboration with other departments and other.

\section{Statistical analyses}

The relationship between specialty, safety culture and outcomes was assessed with multilevel logistic regression analyses, because events were nested within units (Snijders \& Bosker 1999). The multilevel analyses were performed with MLwiN. Patient safety outcomes were the occurrence of seven types of unintended events (without 'other'). For every patient safety outcome (event type), 13 separate multilevel models were fitted: one model with the specialty of the unit as the independent variable, one model with the unit's overall culture score and 11 models with the unit's score on each of the dimensions of safety culture. The nesting was events within hospital units (two levels). The number of units within a hospital was too low to discern the hospital level as a relevant additional level: in most cases, there was only one participating unit per hospital. The reason for estimating separate models, and not integrating multiple independent variables in the same model, was the small number of units (28) at the highest level.

When calculating unit means of the items within a dimension of patient safety culture - resulting in a dimensional score between 0 and 5 - we used the ecometric approach of Raudenbush and Sampson (1999), thus controlling for individual variation.

As we wanted to estimate unit-level effects, we added two event-level variables as covariates in the multilevel model, thereby controlling for compositional effects: the time of the event (daytime 7 a.m. till 5 p.m., evening and night 5 p.m. till 7 a.m. or unknown) and the presence of consequences for the patient (yes or no).

As we wanted to investigate whether patient safety culture mediates the relationship between specialty and event types, we used the procedure of Baron and Kenny (1986): to show mediation, the independent variable must significantly relate to the potential mediator, the mediator must have a significant relationship with the dependent variable, and the relationship between the independent variable and dependent variable should be eliminated (full mediation) or weakened (partial mediation) when the mediator is controlled for. We performed Sobel tests to examine whether the mediation effects were significant (Preacher \& Hayes 2004). The results will be presented in line with the steps of Baron and Kenny's procedure, after a description of the sample characteristics. Because we performed a large number of tests, we will discuss only strong relationships with a significance level of 
Smits, M., Wagner, C., Spreeuwenberg, P., Timmermans, D.R.M., Wal, G. van der, Groenewegem, P.P. The role of patient safety culture in the causation of unintended events in hospital. Journal

of Clinical Nursing: 2012, 21(23-24), 3392-3401

$\mathrm{p}<0 \cdot 01$. Relatively weak relationships $(0 \cdot 01<\mathrm{p}<0 \cdot 05)$ are indicated with an asterisk in the tables, but will not be discussed in the text.

\section{RESULTS}

\section{Characteristics of the sample}

Healthcare professionals at the 28 units reported 1885 events. Table 1 shows the types of events that were reported by each specialty, with some examples for each event category. A quarter of the unintended events were related to medication. In $20 \%$ of the unintended events, there were problems in the cooperation with other departments (Table 1).

\section{[TABLE 1]}

A total of 542 healthcare professionals completed the HSOPS (emergency department $n=217$, surgery $n=173$, internal medicine $n=152$ ), with an average response rate of $56 \%$ (emergency department $72 \%$, surgery $35 \%$, internal medicine $62 \%)$. Most of the respondents were nurses (74\%). Other respondents were resident physicians (10\%), medical specialists (6\%) and managers $(2 \%)$ or had another profession (5\%) (Table 2). The bottom section of Table 1 shows the scores on patient safety culture. Overall, the lowest scores were on the dimensions 'willingness to report', 'hospital management support' and 'teamwork across hospital units'. Units were most positive about 'teamwork within units', 'communication openness' and 'non-punitive response to error'.

\section{[TABLE 2]}

\section{Relationship between specialty and patient safety culture}

We investigated the relationship between specialty and patient safety culture in separate models for each safety culture dimension (Table 3). Surgery and internal medicine units had higher scores on 'willingness to report', 'non-punitive response to error' and 'smooth transitions' than emergency departments. Moreover, internal medicine units perceived more 'hospital management support'.

\section{[TABLE 3]}

\section{Relationship between specialty and event types}

We investigated the relationship between specialty and types of unintended events (Table 4). Healthcare professionals in units of surgery and internal medicine reported more events related to medication, fewer events related to materials and equipment and fewer events concerning collaboration with resident physicians and consultants as compared to staff in emergency departments. 
Smits, M., Wagner, C., Spreeuwenberg, P., Timmermans, D.R.M., Wal, G. van der, Groenewegeph P.P. The role of patient safety culture in the causation of unintended events in hospital. Journal of Clinical Nursing: 2012, 21(23-24), 3392-3401

\section{[TABLE 4]}

\section{Relationship between safety culture and event types}

We investigated the relationship between safety culture and types of unintended events (Table 4). The overall measure of safety culture only related to the collaboration with residents and consultants. Units with higher scores on overall safety culture reported fewer events concerning collaboration with residents/consultants.

The separate analyses for the 11 dimensions of patient safety culture showed that three of these dimensions were related to the occurrence of three types of events: 'willingness to report' (Model 6), 'non-punitive response to error' (Model 9) and 'hospital management support for safety' (Model 13) were related to the occurrence of events reported about medication, materials/equipment and collaboration with resident physicians/consultants. As might be expected, units with more positive scores on 'willingness to report' and 'non-punitive response to error' reported more medication related events. However, units with more 'willingness to report' and perceiving more 'hospital management support' reported fewer events concerning materials/equipment and concerning collaboration with residents/consultants.

\section{Testing for a mediating role of patient safety culture}

For three safety culture dimensions, all requirements for testing mediation were met: 'willingness to report', 'non-punitive response for error' and 'hospital management support'. That is, specialty significantly related to these potential mediators (dimensions of patient safety culture), and the dimensions had a significant relationship with one or more event types (as patient safety outcomes). For the other dimensions, there was no significant relationship of specialty with the potential mediator. Therefore, we only tested whether these three dimensions mediate the relationship between specialty and event types.

Moreover, we only investigated mediation for the following event types: events regarding medication, events regarding materials and equipment and events regarding collaboration with resident physicians and consultants. For the other event types, there was no significant relationship between specialty and the event type. The results in Table 5 show that 'willingness to report' fully mediates the effect of specialty Surgery on two event types. When adding 'willingness to report' to the model (Model a), there is no longer a significant relationship between specialty Surgery and materials/equipment-related events (Sobel $=-2 \cdot 841, \mathrm{p}<0 \cdot 01$ ) and between specialty Surgery and events about collaboration with residents/consultants (Sobel $=-2 \cdot 640, \mathrm{p}<0 \cdot 01$ ). Adding safety culture dimensions to the models slightly influences other relationships as well, indicating partial mediation effects. To test whether the safety culture dimensions partially mediate the relationship between specialty and event types, we conducted Sobel tests for all models in Table 5. In addition to the full mediation effects of 'willingness to report' mentioned above, this safety culture dimension appears to partially mediate the relationship between specialty Surgery and medication events (Sobel $=3 \cdot 017, \mathrm{p}<0 \cdot 01$ ) and between specialty Internal medicine and all three event types (medication Sobel $=2 \cdot 943, \mathrm{p}<$ $0 \cdot 01$; materials/equipment Sobel $=-2 \cdot 144, \mathrm{p}<0 \cdot 01$; collaboration with residents/consultants Sobel $=-2 \cdot 590, p<0 \cdot 01)$. 'Non-punitive response to error' 
Smits, M., Wagner, C., Spreeuwenberg, P., Timmermans, D.R.M., Wal, G. van der, Groenewegeph P.P. The role of patient safety culture in the causation of unintended events in hospital. Journal of Clinical Nursing: 2012, 21(23-24), 3392-3401

partially mediates the relationship between specialty Internal medicine and medication events (Sobel $=2 \cdot 201, \mathrm{p}<0 \cdot 05$ ). 'Hospital management support' appears to partially mediate the relationship between specialty Internal medicine and events related to materials/equipment (Sobel $=-2 \cdot 169, \mathrm{p}<0 \cdot 05)$ and to collaboration with residents/consultants (Sobel $=-2 \cdot 317, \mathrm{p}<0 \cdot 05$ ).

\section{[TABLE 5]}

\section{DISCUSSION}

In this study, we examined the relationship between safety culture and healthcare performance. More specifically, we examined whether patient safety culture mediates the relationship between specialty and types of unintended events. We found only a few significant relationships between safety culture scores and safety outcomes (event types). And only three of the 11 safety culture dimensions played a mediating role in the relationship between specialty and event types (only for some of the event types), with 'willingness to report' as the most important mediating factor. We conclude that our study did not demonstrate that specialties differ in performance because of their safety cultures. It also could not give support for the claim that safety culture is a key factor affecting patient safety.

Other studies found similar results: Scott et al. (2003a) reviewed the evidence for a relationship between organisational culture and healthcare performance. The review included ten studies with diverse definitions of culture and varying measures of healthcare performance. The authors concluded that there is some evidence to suggest that culture is a relevant factor in healthcare performance, but that articulation of the nature of the relationship is difficult. The claim 'strong culture leads to good performance' could not be supported by this review (Scott et al. 2003a). Also, more recent studies failed to identify a clear relationship (Weingart et al. 2004, Hann et al. 2007, Bosch et al. 2008). The limited number of significant associations in our study and in previous studies raises the question whether the current policy emphasising the importance of safety culture for patient safety is misplaced. Our results indicate that the pace and complexity of the work itself inherent to the different specialties might be more important than the safety culture among unit personnel. For example, in surgical and internal medicine units as compared to emergency departments, tasks of healthcare professionals more often include giving medication to patients, resulting in a larger opportunity for medication errors. And emergency departments are highly dependent on other hospital units (for example, the laboratory) in the provision of care for their patients, resulting in a larger likelihood of events concerning the collaboration with other units.

As far as we know, there are no other studies that investigated the triad between specialty, safety culture and safety outcomes. We examined this relationship using a large number of safety culture questionnaires and a large data set of unintended events in multiple units and hospitals, which were collected in the same time period by independent measurements.

We used many dimensions of patient safety culture and many event types. However, as a result of these large quantities of variables, we performed multiple tests. To reduce the chance of type I errors (false positive: observing a relationship when in truth there is none) owing to multiple testing, we needed to reduce the significance level to $\mathrm{p}<0 \cdot 01$. 
Smits, M., Wagner, C., Spreeuwenberg, P., Timmermans, D.R.M., Wal, G. van der, Groenewegeph P.P. The role of patient safety culture in the causation of unintended events in hospital. Journal of Clinical Nursing: 2012, 21(23-24), 3392-3401

Our study has some other limitations. We could not use an outcome that measured the absolute rate of unintended events in the units, because it is unlikely that all unintended events have been reported (no denominator). Moreover, although we had more than 500 respondents of the safety culture questionnaire, we had to estimate unit means to perform our analyses $(n=28)$, because we could not link the reported events to individual respondents to the safety culture questionnaire. This is not a limitation in itself, because the questionnaire measures unit culture and not just individual attitudes (Smits et al. 2009), but it limits the power of the study. Furthermore, the healthcare professionals participating in the survey and in the event reporting were mainly nurses. Only a few resident physicians and medical consultants participated in the study. The results are thus mainly related to nursing culture and nursing care. Finally, there is a debate in the literature concerning whether a quantitative questionnaire is suitable to measure a complex psychological construct like safety culture (Scott et al. 2003b). Some argue that quantitative methods should be accompanied by qualitative methods, like observation, interviewing and participation (Nieva \& Sorra 2003, Flin et al. 2006).

\section{CONCLUSIONS}

Our study showed only a few significant relationships between safety culture and safety outcomes (event types). The safety culture dimension 'willingness to report' was a significant mediating factor of the relationship between specialty and some event types. However, on the whole, we did not find that the safety culture within hospital units provides a clear explanation of differences in safety outcomes between unit types. Our findings suggest that patient safety may not be merely linked to safety culture - or any other one factor - but rather is multidimensional, including aspects of the work itself and characteristics of the patient population, next to the safety culture among staff. More research is needed into the causes of variation in patient safety between hospital units.

\section{RELEVANCE TO CLINICAL PRACTICE}

Our study could not give firm support for the claim that safety culture is a key factor affecting patient safety. We did not find that the culture of a hospital unit explains why units vary in the types of errors that are reported. Variation in safety performance might be more related to the complexity of the work in the units.

\section{ACKNOWLEDGEMENTS}

We would like to thank everyone who contributed to the study: the staff of the participating hospital units and the researchers and nurses who helped with the data collection. The study has been initiated by the Dutch Society of Medical Specialists (in Dutch: Orde van Medisch Specialisten) with financial support from the Ministry of Health, Welfare and Sport.

\section{REFERENCES}

Baker GR, Norton PG, Flintoft V, Blais R, Brown A, Cox J, Etchells E, Ghali WA, Hébert P, Majumdar SR, O'Beirne M, Palacios-Derflingher L, Reid RJ, Sheps S \& Tamblyn R (2004) The Canadian Adverse Events Study: the incidence of adverse events among hospital patients in Canada. Canadian Medical Association Journal170, 1678-1686. 
Smits, M., Wagner, C., Spreeuwenberg, P., Timmermans, D.R.M., Wal, G. van der, Groenewegep, P.P. The role of patient safety culture in the causation of unintended events in hospital. Journal of Clinical Nursing: 2012, 21(23-24), 3392-3401

Baron RM \& Kenny DA (1986) The moderator-mediator variable distinction in social psychological research: conceptual, strategic, and statistical considerations. Journal of Personality and Social Psychology51, 1173-1182.

Battles JB \& Lilford RJ (2003) Organizing patient safety research to identify risks and hazards. Quality and Safety in Health Care12, ii2-ii7.

Bhasale AL, Miller GC, Reid SE \& Britt C (1998) Analysing potential harm in Australian general practice: an incident-monitoring study. Medical Journal of Australia169, 73-76.

Bosch M, Dijkstra R, Wensing M, van der Weijden T \& Grol R (2008) Organizational culture, team climate and diabetes care in small office-based practices. BMC Health Services Research8, 180.

Colla JB, Bracken AC, Kinney LM \& Weeks WB (2005) Measuring patient safety climate: a review of surveys. Quality and Safety in Health Care14, 364-366.

Davies HTO, Nutley SM \& Mannion R (2000) Organisational culture and quality of health care. Quality and Safety in Health Care9, 111-119.

Davis P, Lay-Yee R, Briant R, Ali W, Scott A \& Schug S (2003) Adverse events in New Zealand public hospitals II: preventability and clinical context. New Zealand Medical Journal116, U624.

Flin R, Burns C, Mearns K, Yule S \& Robertson EM (2006) Measuring safety climate in health care. Quality and Safety in Health Care15, 109-115.

Hann M, Bower P, Campbell S, Marshall M \& Reeves D (2007) The association between culture, climate and quality of care in primary healthcare teams. Family Practice24, 323329.

Hartmann CW, Rosen AK, Meterko M, Shokeen P, Zhao S, Singer S, Falwell A \& Gaba DM (2008) An overview of patient safety climate in the VA. Health Services Research43, 12641484.

Health and Safety Commission (HSC) (1993) Organising for Safety: Third Report. ACSNI Study Group on Human Factors. HSE Books, Sudbury.

Kaplan HS \& Rabin Fastman B (2003) Organization of event reporting data for sense making and system improvement. Quality and Safety in Health Care12, ii68-ii72.

Kitch BT (2008) Safety culture. In World Health Organization Alliance for Patient Safety. Summary of the Evidence on Patient Safety: Implications for Research. (Ashish J ed). World Health Organization, Geneva, pp. 54-56.

Nieva VF \& Sorra J (2003) Safety culture assessment: a tool for improving patient safety in healthcare organizations. Quality and Safety in Health Care12, ii17-ii23.

Preacher KJ \& Hayes AF (2004) SPSS and SAS procedures for estimating indirect effects in simple mediation models. Behaviour Research Methods, Instruments, \& Computers34, 717-731.

Raudenbush SW \& Sampson RJ (1999) Ecometrics: toward a science of assessing ecological settings, with application to the systematic social observation of neighborhoods. Sociological Methodology29, 1-41.

van der Schaaf TW. (1992) Near miss reporting in the chemical process industry. (Dissertation). University of Technology, Eindhoven, the Netherlands.

Schein E (1985) Organizational Culture and Leadership. Jossey-Bass, San Francisco.

Scott T, Mannion R, Marshall M \& Davies H (2003a) Does organisational culture influence health care performance? A review of the evidenceJournal of Health Services Research \& Policy8, 105-117.

Scott T, Mannion R, Davies H \& Marshall M (2003b) The quantitative measurement of organisational culture in health care: a review of the available instruments. Health Services Research38, 923-945.

Singer SJ, Gaba DM, Falwell A, Lin S, Hayes J \& Baker L (2009) Patient safety climate in 92 US hospitals: differences by work area and discipline. Medical Care47, 23-31.

Smits M, Christiaans-Dingelhoff I, Wagner C, van der Wal G \& Groenewegen PP (2008) The psychometric properties of the 'Hospital Survey on Patient Safety Culture' in Dutch hospitals. BMC Health Services Research8, 230.

Smits M, Wagner C, Spreeuwenberg P, van der Wal G \& Groenewegen PP (2009) Measuring patient safety culture: an assessment of the clustering of responses at unit level and hospital level. Quality and Safety in Health Care18, 292-296. 
Smits, M., Wagner, C., Spreeuwenberg, P., Timmermans, D.R.M., Wal, G. van der, Groenewege, P.P. The role of patient safety culture in the causation of unintended events in hospital. Journal

of Clinical Nursing: 2012, 21(23-24), 3392-3401

Snijders TAB \& Bosker R (1999) Multilevel Analysis. An Introduction to Basic and Advanced Multilevel Modelling. Sage, London.

Sorra JS \& Nieva VF (2004) Hospital Survey on Patient Safety Culture. Agency for

Healthcare Research and Quality, Rockville, MD.

Sorra J, Famolaro T, Dyer N, Khanna K \& Nelson D (2011) Hospital survey on patient safety culture: 2011 user comparative database report. AHRQ Publication No. 11-0030 . Agency for Healthcare Research and Quality, Rockville, MD. Available at: http://www.ahrq.gov/qual/hospsurvey11 (accessed 2 December 2011).

Vincent C, Neale G \& Woloshynowych M (2001) Adverse events in British hospitals: preliminary retrospective record review. British Medical Journal322, 517-519.

de Vries EN, Ramrattan MA, Smorenburg SM, Gouma DJ \& Boermeester MA (2008) The incidence and nature of in-hospital adverse events: a systematic review. Quality and Safety in Health Care17, 216-223.

Weingart SN, Farbstein K, Davis RB \& Phillips RS (2004) Using a multihospital survey to examine the safety culture. Joint Commission Journal on Quality and Safety30, 125-132.

Zegers M, de Bruijne MC, Wagner C, Hoonhout LHF, Waaijman R, Smits M, Hout FAG, Zwaan L, Christiaans-Dingelhoff I, Timmermans DRM, Groenewegen PP \& van der Wal G (2009) Adverse events and potentially preventable deaths in Dutch hospitals. Results of a retrospective patient record review study. Quality and Safety in Health Care18, 297-302.

Zohar D, Livne Y, Tenne-Gazit O, Admi H \& Donchin Y (2007) Healthcare climate: a

framework for measuring and improving patient safety. Critical Care Medicine35, 13121317.

BOX AND TABLES

Box 1 Diagram of mediation effect of safety culture

\begin{tabular}{|c|c|c|c|c|}
\hline Independent variable & & Mediator & & Outcome \\
\hline Specialty & $\rightarrow$ & Safety culture & $\rightarrow$ & $\begin{array}{l}\text { Unintended event } \\
\text { types }\end{array}$ \\
\hline
\end{tabular}


Smits, M., Wagner, C., Spreeuwenberg, P., Timmermans, D.R.M., Wal, G. van der, Groenewegeph P.P. The role of patient safety culture in the causation of unintended events in hospital. Journal of Clinical Nursing: 2012, 21(23-24), 3392-3401

Table 1 Types of unintended events (observed) and patient safety culture (model-based)

\begin{tabular}{|c|c|c|c|c|}
\hline \multirow[b]{2}{*}{ Unintended events } & \multirow{2}{*}{$\frac{\text { Overall }}{n(\%)}$} & \multirow{2}{*}{$\frac{\text { Emergency }}{n(\%)}$} & \multirow{2}{*}{$\begin{array}{l}\text { Surgery } \\
n(\%)\end{array}$} & \multirow{2}{*}{$\begin{array}{l}\text { Internal } \\
\text { medicine } \\
n(\%)\end{array}$} \\
\hline & & & & \\
\hline \multicolumn{5}{|l|}{ Medication } \\
\hline $\begin{array}{l}\text { e.g. medication expired; medication instruction accomplished } \\
\text { twice; heparin pump was at a too low rate during } 15 \text { hours }\end{array}$ & $458(24 \cdot 3)$ & $38(7 \cdot 3)$ & $226(25 \cdot 7)$ & $194(40 \cdot 2)$ \\
\hline \multicolumn{5}{|l|}{ Collaboration with other departments } \\
\hline $\begin{array}{l}\text { e.g. long waiting time for laboratory test results; technical service } \\
\text { has not fixed door of medication room for months despite repeated } \\
\text { requests; incomplete information during handover between units }\end{array}$ & $375(19 \cdot 9)$ & $128(24 \cdot 5)$ & $194(22 \cdot 0)$ & $53(11.0)$ \\
\hline \multicolumn{5}{|l|}{ Materials and equipment } \\
\hline $\begin{array}{l}\text { e.g. battery of blood pressure device is lacking; error in electronic } \\
\text { record system (unable to look up medical history of patient); defect } \\
\text { of remote control for electronically adjustable bed }\end{array}$ & $233(12 \cdot 4)$ & $106(20-3)$ & $89(10 \cdot 1)$ & $38(7.9)$ \\
\hline \multicolumn{5}{|l|}{ Diagnosis and treatment } \\
\hline $\begin{array}{l}\text { e.g. forgot to disconnect feeding probe; dialysis monitor not tuned } \\
\text { properly; elbow injury overlooked }\end{array}$ & $223(11 \cdot 8)$ & $75(14 \cdot 4)$ & $96(10 \cdot 9)$ & $52(10 \cdot 8)$ \\
\hline \multicolumn{5}{|l|}{ Collaboration with resident physicians and consultants } \\
\hline $\begin{array}{l}\text { e.g. insufficient supervision of resident physicians; consultant does } \\
\text { not come to visit the department to see a patient when requested; } \\
\text { resident or consultant unreachable by telephone }\end{array}$ & $204(10 \cdot 8)$ & $89(17 \cdot 0)$ & $92(104)$ & $23(4 \cdot 8)$ \\
\hline \multicolumn{5}{|l|}{ Incorrect data and substitutions } \\
\hline $\begin{array}{l}\text { e.g. incorrect date on X-ray; patient sent to OR with medical record of } \\
\text { another patient; sticker with personal information of wrong patient pasted } \\
\text { on laboratory request form }\end{array}$ & $104(5 \cdot 5)$ & $39(7 \cdot 5)$ & $49(5 \cdot 6)$ & $16(3 \cdot 3)$ \\
\hline \multicolumn{5}{|l|}{ Protocols and regulations } \\
\hline $\begin{array}{l}\text { e.g. inconsistency in protocols; protocol untraceable on the intranet; staff } \\
\text { unknown with procedure in new protocol }\end{array}$ & $97(5 \cdot 1)$ & $20(3.8)$ & $42(4 \cdot 8)$ & $35(7 \cdot 3)$ \\
\hline \multicolumn{5}{|l|}{ Other } \\
\hline $\begin{array}{l}\text { e.g. fall of patient; patient leaves hospital against medical advice; bad news } \\
\text { brought to patient when his family was not present for support }\end{array}$ & $166(8 \cdot 8)$ & $27(5 \cdot 2)$ & $90(10 \cdot 2)$ & $49(10 \cdot 2)$ \\
\hline Missing & $25(1 \cdot 3)$ & $0(0 \cdot 0)$ & $3(0 \cdot 3)$ & $22(4 \cdot 6)$ \\
\hline Total & $1885(100)$ & $522(100)$ & $881(100)$ & $482(100)$ \\
\hline Safety culture* & Mean (SD) & Mean (SD) & Mean (SD) & Mean (SD) \\
\hline Overall patient safety culture & $3 \cdot 25(0 \cdot 12)$ & $3.23(0 \cdot 10)$ & $3 \cdot 23(0 \cdot 15)$ & $3.31(0.07)$ \\
\hline Dimension: Feedback about and leaming from error & $3 \cdot 17(0 \cdot 20)$ & $3 \cdot 19(0 \cdot 20)$ & $3.09(0.24)$ & $3 \cdot 23(0 \cdot 10)$ \\
\hline Dimension: Overall perceptions of safety & $3 \cdot 03(0 \cdot 18)$ & $2 \cdot 99(0 \cdot 19)$ & $3.01(0 \cdot 19)$ & $3 \cdot 11(0 \cdot 15)$ \\
\hline Dimension: Teamwork across hospital units & $2 \cdot 85(0.08)$ & $2.84(0.08)$ & $2.84(0.08)$ & $2 \cdot 87(0 \cdot 10)$ \\
\hline Dimension: Willingness to report & $2 \cdot 78(0 \cdot 17)$ & $2 \cdot 63(0 \cdot 13)$ & $2.88(0 \cdot 19)$ & $2.87(0.08)$ \\
\hline Dimension: Supervisor/manager expectations $\&$ actions & $3 \cdot 41(0 \cdot 26)$ & $3.54(0.27)$ & $3 \cdot 30(0 \cdot 27)$ & $3.40(0 \cdot 15)$ \\
\hline Dimension: Teamwork within units & $3 \cdot 83(0 \cdot 14)$ & $3.81(0 \cdot 13)$ & $3.84(0 \cdot 17)$ & $3.87(0 \cdot 13)$ \\
\hline Dimension: Non-punitive response to error & $3.57(0 \cdot 12)$ & $3.47(0 \cdot 10)$ & $3.63(0 \cdot 10)$ & $3.62(0.06)$ \\
\hline Dimension: Smooth transitions & $3.40(0.19)$ & $3.25(0.17)$ & $3.48(0.14)$ & $3.50(0.14)$ \\
\hline Dimension: Communication openness & $3.72(0 \cdot 11)$ & $3.75(0 \cdot 12)$ & $3.68(0 \cdot 12)$ & $3.74(0 \cdot 11)$ \\
\hline Dimension: Adequate staffing & $3.20(0.43)$ & $3.27(0 \cdot 41)$ & $3.05(0.53)$ & $3.29(0.28)$ \\
\hline Dimension: Hospital management support & $2.82(0.22)$ & $2 \cdot 76(0 \cdot 14)$ & $2.77(0.25)$ & $2.95(0.24)$ \\
\hline
\end{tabular}

*Higher scores indicate a more positive safety culture (range 0-5). We controlled for individual variation using the ecometric approach of Raudenbush and Sampson.

Table 2 Characteristics of respondents to patient safety questionnaire

\begin{tabular}{|c|c|c|c|c|}
\hline & $\begin{array}{l}\text { Emergency } \\
n=217 \\
n(\%)\end{array}$ & $\begin{array}{l}\text { Surgery } \\
n=173 \\
n(\%)\end{array}$ & $\begin{array}{l}\text { Internal medicine } \\
n=152 \\
n(\%)\end{array}$ & $\begin{array}{l}\text { Total } \\
n=542 \\
n(\%)\end{array}$ \\
\hline Nurse & $177(816)$ & $116(67 \cdot 1)$ & $108(71 \cdot 1)$ & $401(74.0)$ \\
\hline $\begin{array}{l}\text { Resident } \\
\text { physician }\end{array}$ & $23(10 \cdot 6)$ & $15(8.7)$ & $17(11 \cdot 2)$ & $55(10 \cdot 1)$ \\
\hline $\begin{array}{l}\text { Medical } \\
\text { specialist }\end{array}$ & $5(2 \cdot 3)$ & $17(9 \cdot 8)$ & $13(8 \cdot 6)$ & $35(64)$ \\
\hline Manager & $5(2 \cdot 3)$ & $3(1 \cdot 7)$ & $2(1 \cdot 3)$ & $10(1.8)$ \\
\hline Other & $5(2 \cdot 3)$ & $9(5 \cdot 2)$ & $11(7 \cdot 2)$ & $25(4 \cdot 6)$ \\
\hline Missing & $2(0.9)$ & $13(7 \cdot 5)$ & $1(0.7)$ & $16(3 \cdot 0)$ \\
\hline
\end{tabular}


Smits, M., Wagner, C., Spreeuwenberg, P., Timmermans, D.R.M., Wal, G. van der, Groenewege, P.P. The role of patient safety culture in the causation of unintended events in hospital. Journal of Clinical Nursing: 2012, 21(23-24), 3392-3401

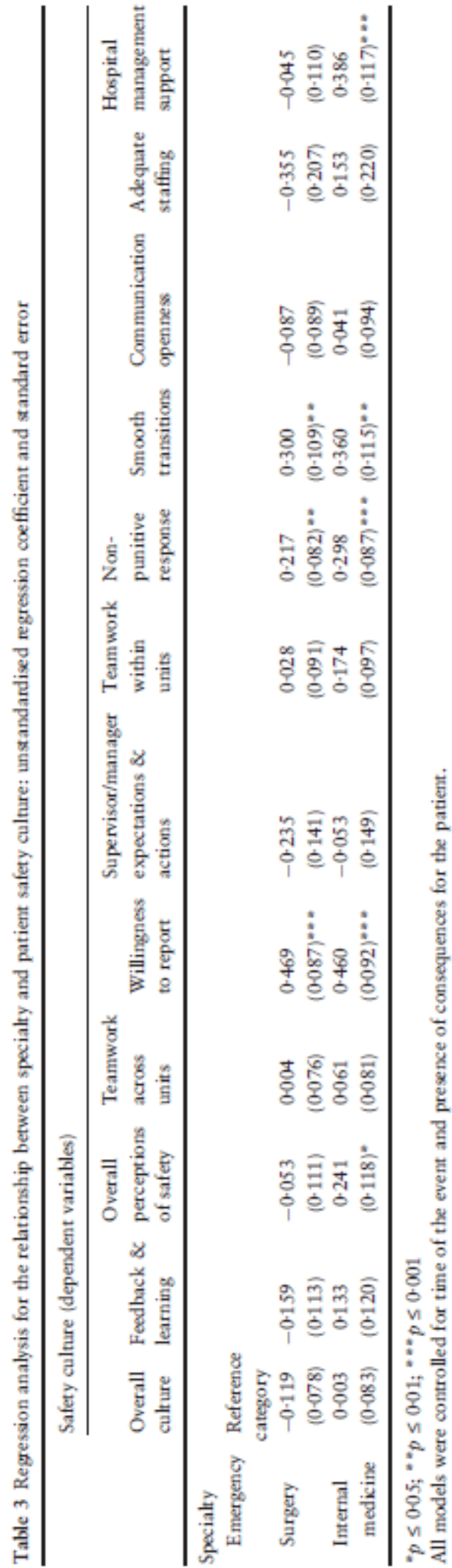


Smits, M., Wagner, C., Spreeuwenberg, P., Timmermans, D.R.M., Wal, G. van der, Groenewegeph P.P. The role of patient safety culture in the causation of unintended events in hospital. Journal

of Clinical Nursing: 2012, 21(23-24), 3392-3401

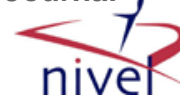

\begin{tabular}{|c|c|c|c|c|c|c|c|c|c|c|}
\hline & 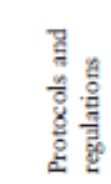 & 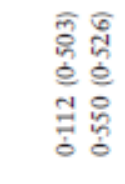 & 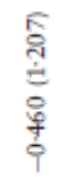 & 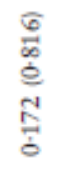 & 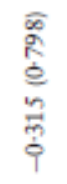 & $\begin{array}{l}\widehat{\text { ปิ }} \\
\stackrel{+}{*} \\
\infty \\
0 \\
0 \\
0\end{array}$ & 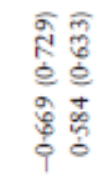 & 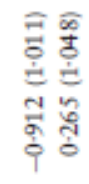 & 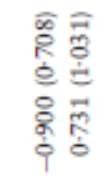 & 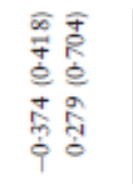 \\
\hline & 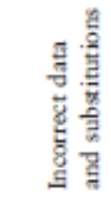 & 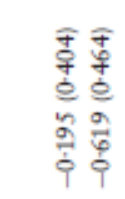 & $\begin{array}{l}\widehat{s} \\
\text { s. } \\
6 \\
0 \\
5 \\
0\end{array}$ & 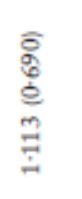 & 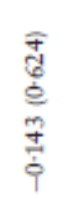 & 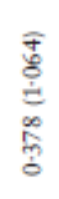 & 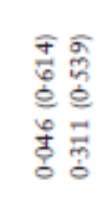 & 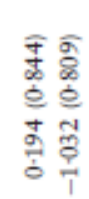 & 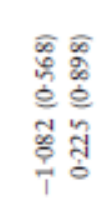 & 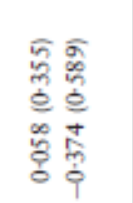 \\
\hline & 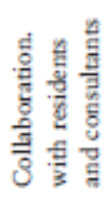 & 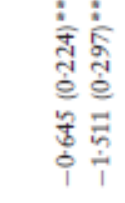 & 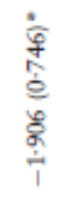 & 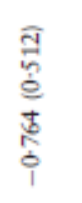 & 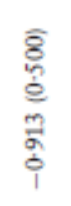 & 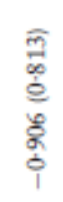 & 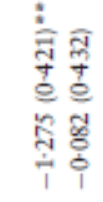 & 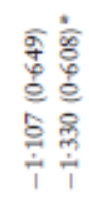 & 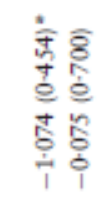 & 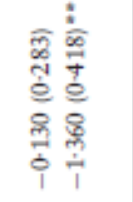 \\
\hline & 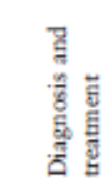 & 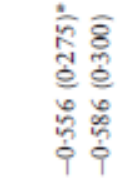 & 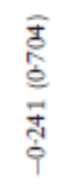 & 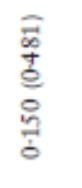 & 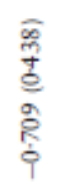 & $\begin{array}{l}\widehat{3} \\
\hat{0} \\
\infty \\
6 \\
0\end{array}$ & 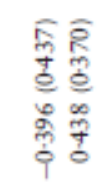 & 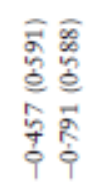 & 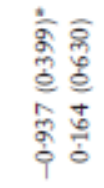 & 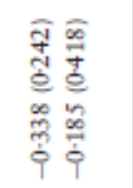 \\
\hline & 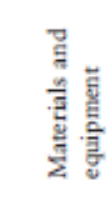 & 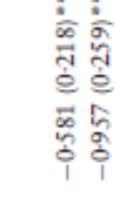 & 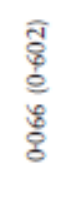 & 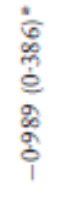 & $\begin{array}{l}\widehat{0} \\
\frac{0}{0} \\
0 \\
0 \\
0 \\
0 \\
1 \\
1\end{array}$ & 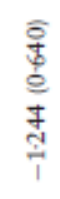 & 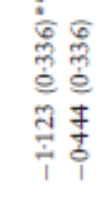 & 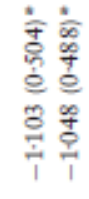 & 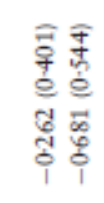 & 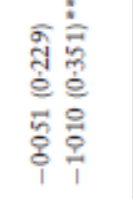 \\
\hline 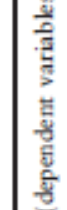 & 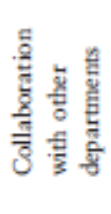 & 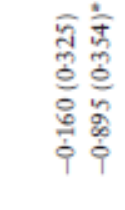 & 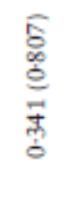 & 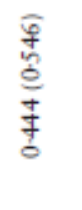 & 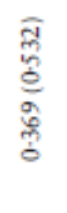 & $\begin{array}{l}\hat{\hat{f}} \\
\text { \& } \\
\stackrel{8}{6} \\
6\end{array}$ & 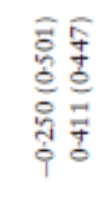 & 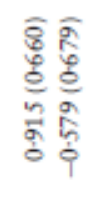 & 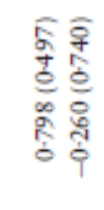 & 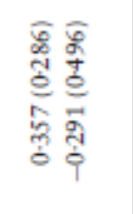 \\
\hline 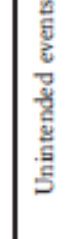 & 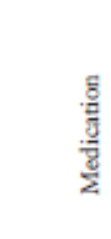 & 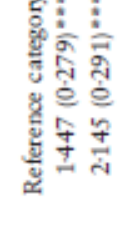 & 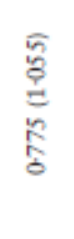 & $\begin{array}{l}\text { तิ } \\
\text { है } \\
\text { dે } \\
\text { i }\end{array}$ & 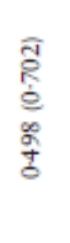 & 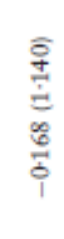 & 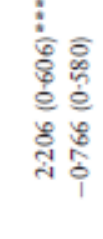 & 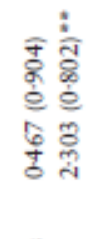 & 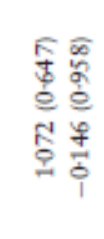 & 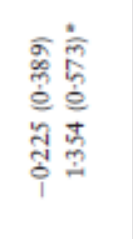 \\
\hline & & 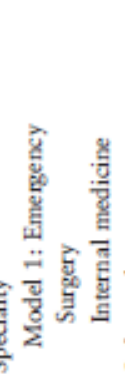 & $\frac{\mathrm{g}}{\mathrm{g}}$ & 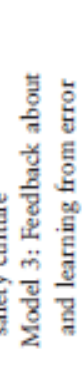 & 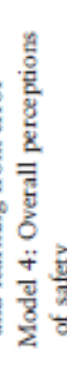 & 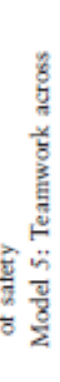 & 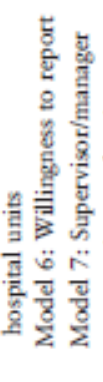 & 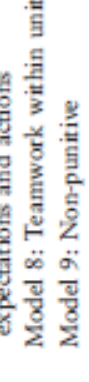 & 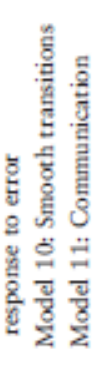 & 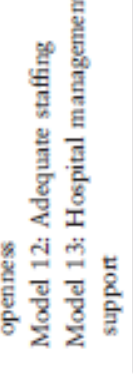 \\
\hline
\end{tabular}


Smits, M., Wagner, C., Spreeuwenberg, P., Timmermans, D.R.M., Wal, G. van der, Groenewegep, P.P. The role of patient safety culture in the causation of unintended events in hospital. Journal of Clinical Nursing: 2012, 21(23-24), 3392-3401

Table 5 Regression analysis for the relationship between specialty, patient safety culture dimensions and types of unintended events: unstandardised regression coefficient and standard error

\begin{tabular}{|c|c|c|c|}
\hline & \multicolumn{3}{|c|}{ Types of unintended events (dependent variables) } \\
\hline & Medication & $\begin{array}{l}\text { Materials and } \\
\text { equipment }\end{array}$ & $\begin{array}{l}\text { Collaboration with } \\
\text { residents and consultants }\end{array}$ \\
\hline \multicolumn{4}{|l|}{ Basic model } \\
\hline \multicolumn{4}{|l|}{ Model 1 (see Tables 3 and 4): } \\
\hline Surgery & $1.447(0.279)^{2 * 2}$ & $-0.581(0-218)^{2 *}$ & $-0-645(0-224)^{22}$ \\
\hline Intemal medicine & $2 \cdot 145(0-291)^{2+2}$ & $-0.957(0.259)^{* 2 *}$ & $-1 \cdot 511(0-297)^{2 * 2}$ \\
\hline Emergency department & Reference & & \\
\hline \multicolumn{4}{|l|}{ Willingness to report } \\
\hline \multicolumn{4}{|l|}{ Model a: } \\
\hline Surgery (ref. Emergency) & $1.484(0.364)^{2+2}$ & $-0.324(0.299)$ & $-0.550(0.310)$ \\
\hline Intemal medicine (ref. Emergency) & $2-183(0-375)^{2+2}$ & $-0.694(0.333)^{*}$ & $-1.412(0-371)^{2+2}$ \\
\hline Willingness to report & $-0-087(0-539)$ & $-0-569(0-461)$ & $-0-216(0-485)$ \\
\hline \multicolumn{4}{|l|}{ Non-punitive response to error } \\
\hline \multicolumn{4}{|l|}{ Model b: } \\
\hline Surgery (ref. Emergency) & $1.433(0-308)^{2=2}$ & $-0.547(0.249)^{2}$ & $-0-647(0-255)^{2}$ \\
\hline Intemal medicine (ref. Emergency) & $2 \cdot 127(0-338)^{2+2}$ & $-0.911(0-307)^{*=}$ & $-1 \cdot 513(0-342)^{\#=*}$ \\
\hline Non-punitive response to error & $0-064(0-577)$ & $-0-148(0-530)$ & $0-009(0-564)$ \\
\hline \multicolumn{4}{|l|}{ Hospital management support } \\
\hline \multicolumn{4}{|l|}{ Model c: } \\
\hline Surgery (ref. Emergency) & $1.447(0.274)^{272}$ & $-0.580(0-202)^{* *}$ & $-0-646(0-208)^{2 *}$ \\
\hline Intemal medicine (ref. Emergency) & $1.997(0.324)^{24=}$ & $-0.686(0.278)^{2}$ & $-1-230(0-317)^{2+2}$ \\
\hline Hospital management support & $0-370(0-401)$ & $-0.717(0.354)^{2}$ & $-0.716(0-381)$ \\
\hline
\end{tabular}

" $p \leq 0-05 ; " * p \leq 0-01 ; * * p \leq 0001$

All models were controlled for time of the event and presence of consequences for the patient.

Regression coefficients in italics indicate partial mediation: regression coefficient was significant in the basic model and decreases considerably after adding the safety culture variable to the model (indicated by a significant Sobel test).

Regression coefficients in both italics and bold indicate full mediation: regression coefficient was significant in basic model and completely bses significance after adding the safety culture variable to the model. 